\title{
Separation and Quantification of Eight Antidiabetic Drugs on A High-Performance Liquid Chromatography: Its Application to Human Plasma Assay
}

\author{
Karunanidhi S. Lakshmi and Tirumala Rajesh \\ Department of Pharmaceutical Analysis, SRM College of Pharmacy, SRM University, Kattankulathur, Tamil Nadu 603203, India \\ Correspondence should be addressed to Tirumala Rajesh, rajeshtirumala@hotmail.com
}

Received 30 March 2011; Accepted 5 May 2011

Academic Editor: N. El-Enany

Copyright ( $) 2011$ K. S. Lakshmi and T. Rajesh. This is an open access article distributed under the Creative Commons Attribution License, which permits unrestricted use, distribution, and reproduction in any medium, provided the original work is properly cited.

\begin{abstract}
An analytical method based on isocratic reverse phase high-performance liquid chromatography was developed and validated for the separation and quantification of eight antidiabetic drugs: rosiglitazone, pioglitazone, glipizide, gliclazide, repaglinide, nateglinide, glibenclamide, and glimepiride for their application in human plasma assay. Metformin is used as internal standard. Analysis was done on Onyx monolithic $\mathrm{C}_{18}$ column $(100 \times 4.6 \mathrm{~mm}$, i.d., $5 \mu \mathrm{m})$ using a mixture of $0.05 \%$ formic acid in water and methanol in the ratio of $42: 58(\mathrm{v} / \mathrm{v})$ fixed at a flow rate of $0.5 \mathrm{~mL} / \mathrm{min}$, and they were monitored at $234 \mathrm{~nm}$. Separation was achieved in less than $20 \mathrm{~min}$. The calibration curves were linear in the range of $50-2000 \mathrm{ng} / \mathrm{mL}$. The method was validated for its recovery, intra- and interday precision, stability, specificity, and selectivity. Plasma samples were prepared using solid-phase extraction of analytes. Hence, the developed method was found to be suitable for the routine analysis of selected antidiabetic drugs in biological matrices.
\end{abstract}

\section{Introduction}

Diabetes mellitus is a heterogeneous group of disorders characterized by abnormalities in carbohydrate, protein, and lipid metabolism [1]. The central disturbance in diabetes mellitus is an abnormality in insulin production or action or both, although other factors can be involved. This results primarily in elevated fasting and postprandial blood glucose levels. In recent years, diabetes mellitus has become a common disease affecting human health seriously. There are estimated 150 million people worldwide sufferings from diabetes, this number may probably double by the year 2030. Reports from the World Health Organization (WHO) indicate that diabetes mellitus is one of the major killers of our time, with people in South East Asia and Western Pacific being most at risk. Therefore, the human population worldwide appears to be in the midst of an epidemic of diabetes. About $90 \%$ of diabetes patients are found to be affected with type II (non-insulin-dependent) diabetes mellitus. It is especially important to ensure the quality of antidiabetic drugs for type II in which insulin deficiency is less severe.
All anti-diabetic drugs (structures shown Figures 1(a), 1(b), 1(c), 1(d), 1(e), 1(f), 1(g), and 1(h)) chosen in this study are commonly used in clinic for type II diabetes mellitus patients. Thiazolidinedione class of drugs (Rosiglitazone (ROS) and Pioglitazone (PIO)) exert their glucose-lowering effect by binding to peroxisome proliferator-activated receptors gamma (PPAR $\gamma)$, thus increasing the receptor sensitivity to insulin [2-4]. Sulfonylurea drugs (Glipizide (GLP), Gliclazide (GLC), Glibenclamide (GLB), and Glimepiride (GLM)) act by increasing the secretion of insulin by the functioning $\beta$ cells of the pancreas. This generation of hypoglycemic drugs are much more potent and are therefore effective at much lower dosages [5]. Repaglinide (REP) also acts by stimulating insulin secretion of $\beta$ cells, but it binds to sites distinct from the sulfonylurea binding sites [6] and Nateglinide (NGL), functions by increasing pancreatic $\beta$ cell sensitivity to ambient glucose without increasing basal insulin secretion $[7,8]$.

In the literature survey, HPLC gradient method for six anti-diabetic drugs in human plasma [9], an isocratic 
<smiles>[R9][Z10]#[R]O[Na]</smiles>

(a)<smiles>Cc1cnc(C(=O)NCCc2ccc(S(=O)(=O)NC(=O)NC3CCCCC3)cc2)cn1</smiles>

(c)<smiles>[R20]C1CCCCC1(C(=O)O)C(=O)OCC</smiles>

(e)<smiles>COc1ccc(Cl)cc1C(=O)NCCc1ccc(S(=O)(=O)NC(=O)NC2CCCCC2)cc1</smiles>

(g)

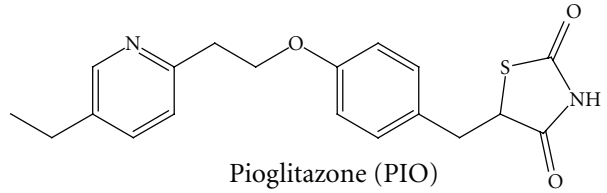

(b)<smiles>Cc1ccc(S(=O)(=O)NC(=O)NN2CC3CCCC3C2)cc1</smiles>

(d)

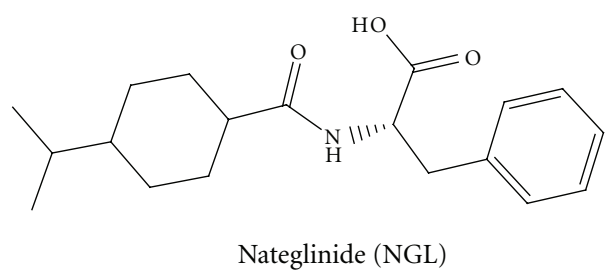

(f)<smiles>CCC1=C(C)CN(C(=O)NCCc2ccc(S(=O)(=O)NC(=O)NC3CCC(C)CC3)cc2)C1=O</smiles>

(h)

FIgure 1: Structural representation of Rosiglitazone (ROS), Pioglitazone (PIO), Glipizide (GLP), Gliclazide (GLC), Repaglinide (REP), Nateglinide (NGL), Glibenclamide (GLB), and Glimepiride (GLM).

method for counterfeit drugs in pharmaceutical formulations [10], and an HPLC method in human plasma for metformin with three sulfonylurea drugs glibenclamide, glipizide, and gliclazide [11] were reported along with few other LC-MS, HPLC, and HPTLC methods confined to single or two drugs in combination [12-27].

The present paper describes an isocratic method for the separation and quantification of eight anti-diabetic drugs using reverse phase HPLC-UV, as the usage of combination of thiazolidinediones and sulfonyl ureas was found to be successful in the treatment of type II diabetes, the method would help in assay of drugs in a single run which reduces the time of analysis and does not require separate methods for each drug. The developed method was also validated successfully applied for human plasma assay.

\section{Materials and Methods}

2.1. Chemicals and Reagents. PIO, GLP, REP, and Metformin (IS) were obtained from Macleoids Pharmaceuticals Ltd., Mumbai, India. GLC, GLB were obtained from Medley Pharmaceuticals, Diu and Daman, India. ROS and GLM were obtained from Orchid Chemicals and Pharmaceuticals, Chennai, India. NGL was obtained from Divis Pharmaceuticals, Hyderabad, India with more than $99 \%$ purity. Methanol (Qualigens, Mumbai, India) HPLC grade was used. SPE cartridges (Oasis HLB $3 \mathrm{~mL}, 60 \mathrm{mg}$, Waters, Milford, MA, USA) were used. All the reagents used were of analytical reagent grade. Milli-Q water (Millipore Q-Gard) was used throughout the analysis.

2.2. Instrumentation. The HPLC system consisted of Shimadzu (Kyoto, Japan) Class LC-10AT vp and LC-20AD pumps connected with SPD-10A vp UV-Visible detector. The data acquisition was performed by Spincotech 1.7 version software (Spinco Biotech Ltd., Chennai, India) and monitored at a wavelength of $234 \mathrm{~nm}$. Samples were injected using $25 \mu \mathrm{L}$ Hamilton syringe.

2.3. Chromatographic Conditions. A reverse phase Onyx monolithic $\mathrm{C}_{18}$ column $(100 \times 4.6 \mathrm{~mm}$ i.d., $5 \mu \mathrm{m}$, Phenomenex, Torrance, USA) was used for separation. The mobile phase consisted of $0.05 \%$ formic acid in water as 
TABLE 1: Results of the linearity, LLOQ, and system suitability parameters $(n=3)$.

\begin{tabular}{lcccccccccc}
\hline Compound & $\lambda_{\max }$ & LLOQ $(\mathrm{ng} / \mathrm{mL})$ & $r^{2}$ & $t_{r}$ & $k^{\prime}$ & $R_{s}$ & $T_{f}$ & $W_{(5 \%)}$ & $N$ & HETP $(\mathrm{mm})$ \\
\hline ROS & 245 & 24 & 0.9983 & 3.14 & 2.31 & - & 1.17 & 0.2876 & 9945 & 0.0101 \\
PIO & 265 & 36 & 0.9981 & 4.58 & 4.59 & 2.42 & 1.09 & 0.2912 & 9233 & 0.0108 \\
GLP & 270 & 35 & 0.9989 & 7.46 & 2.17 & 5.52 & 1.34 & 0.2764 & 10637 & 0.0094 \\
GLC & 225 & 30 & 0.9990 & 8.95 & 2.72 & 3.14 & 1.27 & 0.2819 & 7425 & 0.0135 \\
REP & 245 & 20 & 0.9987 & 12.17 & 3.11 & 7.01 & 1.25 & 0.3011 & 9910 & 0.0101 \\
NGL & 231 & 20 & 0.9989 & 14.39 & 2.79 & 3.47 & 1.42 & 0.3082 & 8941 & 0.0112 \\
GLB & 228 & 40 & 0.9978 & 16.32 & 2.09 & 7.46 & 1.37 & 0.2941 & 10003 & 0.0099 \\
GLM & 246 & 38 & 0.9987 & 18.78 & 2.57 & 2.89 & 1.28 & 0.2659 & 9081 & 0.0110 \\
\hline
\end{tabular}

$t_{r}$ : retention time; $k^{\prime}$ : capacity factor; $R_{s}$ : resolution; $T_{f}$ : tailing factor; $W_{5 \%}:$ width of peak at $5 \%$; $N$ theoretical plates (USP); HETP: height equivalent to theoretical plate Length of the column $(\mathrm{mm}) /$ theoretical plates.

TABLE 2: Summary of precision and accuracy from QC samples in plasma $(n=6)$.

\begin{tabular}{|c|c|c|c|c|c|c|c|}
\hline \multirow[t]{2}{*}{ Compound } & \multirow{2}{*}{$\begin{array}{l}\text { Spiked concentration } \\
(\mathrm{ng} / \mathrm{mL})\end{array}$} & \multicolumn{3}{|c|}{ Intraday } & \multicolumn{3}{|c|}{ Interday } \\
\hline & & Mean \pm SD & $\%$ RSD & Nominal (\%) & Mean \pm SD & $\%$ RSD & Nominal (\%) \\
\hline \multirow{3}{*}{ ROS } & 53.7 & $53.4 \pm 3.7$ & 6.93 & 99.4 & $53.0 \pm 3.6$ & 6.79 & 98.6 \\
\hline & 489.2 & $481.6 \pm 19.9$ & 4.13 & 98.4 & $481.9 \pm 20.7$ & 4.29 & 98.5 \\
\hline & 1531.0 & $1520.5 \pm 129.5$ & 8.51 & 99.3 & $1521.7 \pm 117.8$ & 7.74 & 99.3 \\
\hline \multirow{3}{*}{$\mathrm{PIO}$} & 48.9 & $48.6 \pm 3.5$ & 7.20 & 99.4 & $48.1 \pm 2.9$ & 6.02 & 98.3 \\
\hline & 491.2 & $490.5 \pm 16.2$ & 3.30 & 99.8 & $492.0 \pm 15.9$ & 3.23 & 100.1 \\
\hline & 1513.8 & $1492.3 \pm 132.9$ & 8.90 & 98.5 & $1497.0 \pm 125.6$ & 8.39 & 98.8 \\
\hline \multirow{3}{*}{ GLP } & 50.6 & $52.1 \pm 3.3$ & 6.33 & 102.9 & $50.9 \pm 4.0$ & 7.85 & 100.6 \\
\hline & 492.3 & $504.7 \pm 18.9$ & 3.74 & 102.5 & $499.3 \pm 19.9$ & 3.98 & 101.4 \\
\hline & 1498.5 & $1506.1 \pm 109.2$ & 7.25 & 100.5 & $1500.1 \pm 130.2$ & 8.67 & 100.1 \\
\hline \multirow{3}{*}{ GLC } & 46.8 & $48.2 \pm 3.9$ & 8.09 & 102.9 & $48.2 \pm 4.1$ & 8.50 & 102.9 \\
\hline & 486.7 & $492.9 \pm 15.8$ & 3.20 & 101.2 & $490.8 \pm 18.5$ & 3.76 & 100.8 \\
\hline & 1467.0 & $1479.0 \pm 119.2$ & 8.05 & 100.8 & $1475.6 \pm 125.6$ & 8.51 & 100.5 \\
\hline \multirow{3}{*}{ REP } & 49.2 & $51.1 \pm 2.9$ & 5.67 & 103.8 & $48.9 \pm 3.8$ & 7.77 & 99.3 \\
\hline & 493.4 & $486.8 \pm 15.9$ & 3.26 & 98.6 & $487.1 \pm 17.3$ & 3.55 & 98.7 \\
\hline & 1502.7 & $1489.4 \pm 123.7$ & 8.30 & 99.1 & $1486.9 \pm 91.7$ & 6.16 & 98.9 \\
\hline \multirow{3}{*}{ NGL } & 52.9 & $51.7 \pm 3.1$ & 5.99 & 97.7 & $51.5 \pm 3.0$ & 5.82 & 97.4 \\
\hline & 478.6 & $492.5 \pm 17.2$ & 3.49 & 102.9 & $490.2 \pm 16.9$ & 3.44 & 102.4 \\
\hline & 1439.6 & $1452.4 \pm 134.1$ & 9.23 & 100.9 & $1442.3 \pm 121.3$ & 8.41 & 100.1 \\
\hline \multirow{3}{*}{ GLB } & 45.7 & $45.4 \pm 3.2$ & 7.04 & 99.3 & $44.9 \pm 4.1$ & 9.13 & 98.2 \\
\hline & 478.5 & $481.3 \pm 28.8$ & 5.98 & 100.6 & $479.6 \pm 20.9$ & 4.35 & 100.2 \\
\hline & 1452.0 & $1450.3 \pm 110.1$ & 7.58 & 99.8 & $1451.9 \pm 97.9$ & 6.74 & 99.9 \\
\hline \multirow{3}{*}{ GLM } & 48.6 & $49.1 \pm 2.9$ & 5.90 & 101.0 & $48.5 \pm 3.5$ & 7.21 & 99.7 \\
\hline & 490.5 & $499.6 \pm 25.6$ & 5.12 & 101.8 & $492.8 \pm 24.3$ & 4.93 & 100.4 \\
\hline & 1477.5 & $1479.0 \pm 121.1$ & 8.18 & 100.1 & $1470.8 \pm 115.9$ & 7.88 & 99.5 \\
\hline
\end{tabular}

solvent A and methanol as solvent B. A linear isocratic was run at $0.5 \mathrm{~mL} / \mathrm{min}$ consisting of solvent $\mathrm{A}$ and $\mathrm{B}$ in the ratio of $42: 58 \mathrm{v} / \mathrm{v}$. The injection volume was $20 \mu \mathrm{L}$.

2.4. Preparation of Standard and Sample Solutions. Stock solution of ROS, PIO, GLP GLC, REP, NGL, GLB, and GLM was prepared individually by dissolving $25 \mathrm{mg}$ of each drug in methanol and diluted to $25 \mathrm{~mL}$ to get a final concentration of $1000 \mu \mathrm{g} / \mathrm{mL}$. A series of working standard solutions were prepared by transferring appropriate quantity in order to get a calibration range of 50, 100, 500, 1000, 1500, and $2000 \mathrm{ng} / \mathrm{mL}$ by using methanol. IS was prepared at a concentration of $1000 \mathrm{ng} / \mathrm{mL}$ in methanol.

2.5. Extraction of Drugs from Plasma. Solid-phase extraction was used to preconcentrate the analytes from the human plasma. All the samples were extracted from human plasma using Oasis HLB $3 \mathrm{~mL}, 60 \mathrm{mg}$ (Waters, Milford, MA, USA), solid-phase extraction cartridges. Each cartridge was equilibrated and conditioned by acetonitrile, ultra pure water of $1 \mathrm{~mL}$ each. Samples were added to plasma and vortexmixed for $3 \mathrm{~min}$. Thereafter, the sample was loaded onto 
TABLE 3: Stability data for anti-diabetic drugs in plasma.

\begin{tabular}{|c|c|c|c|c|c|c|c|}
\hline \multirow[t]{3}{*}{ Drug } & \multirow{3}{*}{$\begin{array}{l}\text { Nominal concentration } \\
\mathrm{ng} / \mathrm{mL}\end{array}$} & \multicolumn{6}{|c|}{ Sample conditions (mean \pm S.D) } \\
\hline & & \multicolumn{2}{|c|}{ Short-term ${ }^{\mathrm{a}}$} & \multicolumn{2}{|c|}{ Long-term ${ }^{\mathrm{b}}$} & \multicolumn{2}{|c|}{ Freeze-thaw ${ }^{c}$} \\
\hline & & Nominal (\%) & RSD & Nominal (\%) & RSD & Nominal (\%) & RSD \\
\hline \multirow[t]{2}{*}{ ROS } & 53.7 & 103.1 & 6.2 & 97.5 & 8.6 & 102.4 & 7.1 \\
\hline & 1531.0 & 99.3 & 2.0 & 98.0 & 2.2 & 98.7 & 1.7 \\
\hline \multirow[t]{2}{*}{$\mathrm{PIO}$} & 48.9 & 102.0 & 5.9 & 97.1 & 8.8 & 100.6 & 5.9 \\
\hline & 1513.8 & 99.0 & 2.0 & 97.2 & 1.9 & 99.1 & 1.8 \\
\hline \multirow[t]{2}{*}{ GLP } & 50.6 & 98.9 & 7.6 & 95.6 & 8.0 & 97.1 & 6.6 \\
\hline & 1498.5 & 99.3 & 1.5 & 98.7 & 1.4 & 99.8 & 0.9 \\
\hline \multirow[t]{2}{*}{ GLC } & 46.8 & 105.7 & 8.7 & 99.6 & 3.4 & 100.1 & 2.3 \\
\hline & 1467.0 & 97.8 & 2.0 & 97.3 & 4.1 & 98.1 & 4.5 \\
\hline \multirow[t]{2}{*}{ REP } & 49.2 & 107.8 & 8.9 & 99.2 & 3.8 & 99.2 & 3.0 \\
\hline & 1502.7 & 103.5 & 6.1 & 98.1 & 0.8 & 98.6 & 1.4 \\
\hline \multirow[t]{2}{*}{ NGL } & 52.9 & 98.9 & 11.1 & 96.7 & 7.2 & 96.9 & 5.3 \\
\hline & 1439.6 & 108.0 & 6.4 & 99.0 & 4.8 & 98.5 & 2.8 \\
\hline \multirow[t]{2}{*}{ GLB } & 45.7 & 95.4 & 13.2 & 95.1 & 10.6 & 95.5 & 7.8 \\
\hline & 1452.0 & 97.8 & 10.1 & 96.8 & 6.8 & 96.2 & 5.9 \\
\hline \multirow[t]{2}{*}{ GLM } & 48.6 & 103.7 & 11.6 & 99.1 & 1.9 & 98.7 & 2.2 \\
\hline & 1477.5 & 106.3 & 6.0 & 98.7 & 2.3 & 98.6 & 1.0 \\
\hline
\end{tabular}

${ }^{\mathrm{a}}$ Exposed at room temperature for $24 \mathrm{~h}$.

${ }^{\mathrm{b}}$ Stored at $-70^{\circ} \mathrm{C}$.

${ }^{\mathrm{c}}$ After three freeze-thaw cycles.

TABle 4: Recovery of eight anti-diabetic drugs from plasma samples spiked with each drug spiked.

\begin{tabular}{|c|c|c|c|c|c|c|c|c|}
\hline \multirow[t]{2}{*}{ Compound } & \multicolumn{4}{|c|}{ Concentrations (ng/mL) } & \multicolumn{4}{|c|}{$\%$ recovery and \% RSD } \\
\hline & LLOQ & LQC & MQC & HQC & LLOQ & LQC & MQC & HQC \\
\hline ROS & 24.3 & 53.7 & 489.2 & 1531.0 & $80.1,9.1$ & $77.2,11.3$ & $81.5,7.2$ & $83.4,6.9$ \\
\hline $\mathrm{PIO}$ & 36.1 & 48.9 & 491.2 & 1513.8 & $82.4,7.3$ & $80.6,10.1$ & $81.9,8.1$ & $82.3,7.2$ \\
\hline GLP & 35.6 & 50.6 & 492.3 & 1498.5 & $80.9,6.7$ & $81.9,14.7$ & $82.3,7.7$ & $84.0,9.8$ \\
\hline GLC & 30.5 & 46.8 & 486.7 & 1467.0 & $79.9,5.9$ & $84.5,12.6$ & $83.2,11.1$ & $79.7,13.9$ \\
\hline REP & 20.2 & 49.2 & 493.4 & 1502.7 & $84.5,4.9$ & $80.8,14.2$ & $80.9,8.7$ & $82.4,9.7$ \\
\hline NGL & 20.6 & 52.9 & 478.6 & 1439.6 & $80.8,8.8$ & $83.4,13.7$ & $82.1,12.4$ & $80.9,10.6$ \\
\hline GLB & 40.1 & 45.7 & 478.5 & 1452.0 & $79.1,10.3$ & $75.5,12.2$ & $78.9,12.7$ & $76.8,12.3$ \\
\hline GLM & 38.4 & 48.6 & 490.5 & 1477.5 & $81.2,10.7$ & $78.2,11.0$ & $80.1,4.7$ & $80.1,10$. \\
\hline
\end{tabular}

and passed through the cartridge without lab vacuum and the analytes were then eluted with $1 \mathrm{~mL}$ of acetonitrile. The eluent was evaporated to dryness at $40^{\circ} \mathrm{C}$ under a stream of nitrogen. The dried extract was then reconstituted with $100 \mu \mathrm{L}$ of mobile phase, and a $20 \mu \mathrm{L}$ was injected into the chromatographic system.

2.6. Method Validation. The proposed method was validated in the light of FDA Guidelines for linearity, precision, sensitivity and selectivity, stability and recovery [28, 29].

\section{Results and Discussion}

3.1. Development and Optimization of Chromatographic Conditions. Optimization of the chromatographic conditions are intended to take into account the various goals of method development and to weigh each goal (resolution, runtime, sensitivity, peak symmetry, etc.) accurately, according to the requirement of LC-MS and HPLC methods being used for the estimation of drugs in biological fluids.

The drugs are not totally soluble in water whereas soluble in organic solvents like methanol and acetonitrile. During the development phase, the mobile phase containing acetonitrile water resulted in asymmetric peaks with poor resolution and greater tailing factor $(>2)$ and high run time. The successful use of mobile phase containing a mixture of $0.05 \%$ formic acid and methanol in the ratio of $42: 58 \mathrm{v} / \mathrm{v}$ fixed at the flow rate $0.5 \mathrm{~mL} / \mathrm{min}$ reduced tailing $(<1.5)$ and resulted in good peak symmetry and resolution $(>1.5)$. Methanol was selected because of its favorable UV transmittance, low viscosity, and better solubility. The analytes were monitored at $234 \mathrm{~nm}$ and the retention times were found to be $3.14,4.58,7.46,8.95$, $12.17,14.39,16.32$ and $18.78 \mathrm{~min}$ for ROS, PIO, GLP, GLC, REP, NGL, GLB, and GLM, respectively, and IS was eluted at $2.36 \mathrm{~min}$ (Figure 2). 


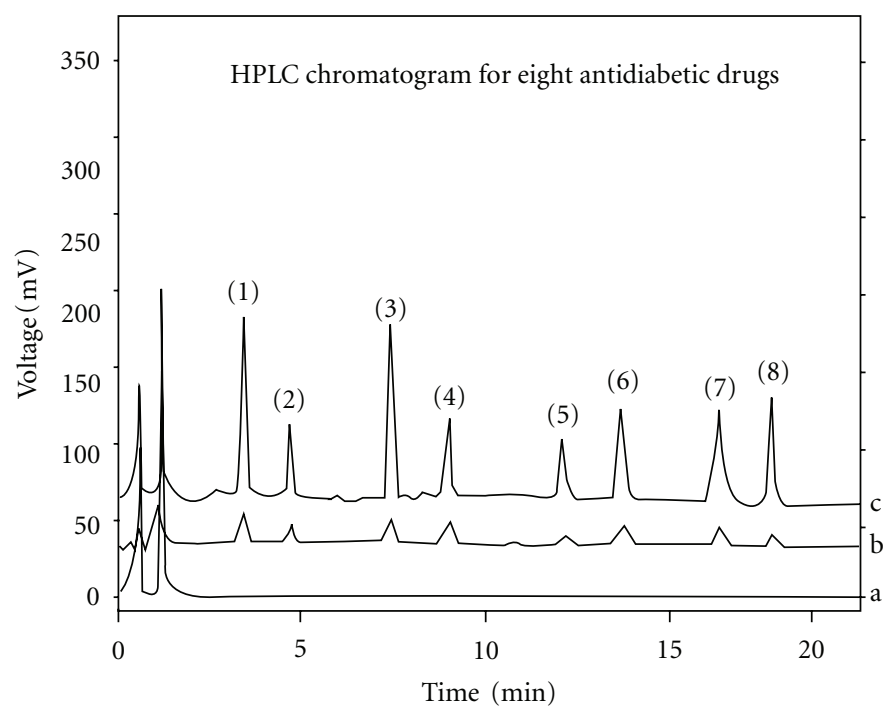

FIgURE 2: (a) Chromatogram showing blank, (b) chromatogram showing anti-diabetic drugs at LLOQ concentration levels, and (c) chromatogram showing drugs at $1000 \mathrm{ng} / \mathrm{mL}$ extracted from human plasma (1) ROS, (2) PIO, (3) GLP, (4) GLC, (5) REP, (6) NGL, (7) GLB, and (8) GLM.

\subsection{Validation of the Developed Method}

3.2.1. Linearity and Calibration Curve. The linearity was tested at the concentration range of $50-2000 \mathrm{ng} / \mathrm{mL}$ and the calibration curve constructed was evaluated by its correlation coefficient. The correlation coefficient $\left(r^{2}\right)$ for all the calibration curves was consistently greater than $0.9984 \pm$ 0.0006 (Table 1).

3.2.2. Method Sensitivity and Specificity. Within the same 30min LC run, all the drugs at $50 \mathrm{ng} / \mathrm{mL}$ each under investigation could be easily detected from human plasma matrices ( $n=10)$. Confirmation of these drugs could be readily achieved by comparing the retention times obtained from the sample with those of their corresponding drug standards. The lower limit of quantification (LLOQ) (Table 1) was defined as the lower concentration that could consistently produce accurate and precise chromatogram that could be quantified. Figure 2-b shows the chromatogram of the drugs obtained from plasma and samples spiked with the concentration at LLOQ.

The method specificity was assessed with different plasma samples ( $n=30$ each, each from different plasma sources) analyzed with the described method. Interferences from the matrices at the targeted retention times were not observed.

3.2.3. Precision and Accuracy. The intraday precision (expressed by coefficient of variation of replicate analyses) was estimated on the three quality control levels and the interday precision on the nine calibration standard levels. Table 2 shows the results obtained for the intraassay (variation intraday) and inter-assay (variation inter-day) precision for drugs. The precision for all these analytes under investigation did not exceed $15 \%$ at any of the concentrations studied and well met the requirements of validation.

3.2.4. Stability. The stability of samples reconstituted after extraction from plasma (as in experimental section) was investigated under various storage conditions. Short-term stability was studied at room temperature for $8 \mathrm{~h}$, longterm stability studies were done at $-70^{\circ} \mathrm{C}$ for $30 \mathrm{~d}$, and freeze-thaw stability was also evaluated by successive cycles of freezing and thawing the samples by storing at $-70^{\circ} \mathrm{C}$ and room temperature, respectively. Three complete freezethaw cycles were performed. They were carried out at two concentration levels (low and high QC) at six replicates. The percentage stability was estimated by comparing the mean of back calculated concentrations of all analytes from the stored stability samples with that of freshly spiked QC samples. The results indicated that each analyte had an acceptable stability under those conditions, as shown in Table 3.

3.3. Recovery of Drugs from Human Plasma. Solid-phase extraction technique was found to be successful in extraction of eight anti-diabetic drugs from human plasma and the recovery was determined by comparing peak areas of spiked plasma extracts with those of unextracted neat standards freshly prepared in methanol. Plasma samples $(n=6)$ spiked with the analytes at their respective LLOQ, low, middle and high QC levels were analyzed. The area ratios of the targeted drugs were compared with those obtained from blank extracts spiked with the 8 target drugs after extraction (taken as $100 \%$ recovery of the drug from that particular matrix). Recoveries of the drugs are summarized in Table 4. 


\section{Conclusion}

A simple, specific, selective, and precise method was developed for the determination of anti-diabetic drugs ROS, PIO, GLP, GLC, REP, NGL, GLB, and GLM. The mobile phase is economical and simple to prepare with little or no variations. The run time $30 \mathrm{~min}$ indicates short analysis time. The sample recoveries in human plasma were in good agreement and they suggested no interference in the estimation. Hence, this method can be easily and conveniently used for the routine analysis of the drug in plasma samples for pharmacokinetic studies.

\section{Acknowledgments}

T. Rajesh is grateful to University Grants Commission (UGC), New Delhi, India for providing Junior Research Fellowship (JRF) and to Dr. R. Shiva Kumar, Pro-Vice Chancellor, SRM University, Kattankulathur for providing the facilities to carry this research work.

\section{References}

[1] C. R. Craig and R. E. Stitzel, Modern Pharmacology with Clinical Applications, Lippincott Williams \& Wilkins, Philadelphia, $\mathrm{Pa}$, USA, 6th edition, 2008.

[2] J. M. Lehmann, L. B. Moore, T. A. Smith-Oliver, W. O. Wilkison, T. M. Willson, and S. A. Kliewer, "An antidiabetic thiazolidinedione is a high affinity ligand for peroxisome proliferator-activated receptor $\gamma$ (PPAR $\gamma)$," Journal of Biological Chemistry, vol. 270, no. 22, pp. 12953-12956, 1995.

[3] T. M. Willson, J. E. Cobb, D. J. Cowan et al., "The structureactivity relationship between peroxisome proliferatoractivated receptor $\gamma$ agonism and the antihyperglycemic activity of thiazolidinediones," Journal of Medicinal Chemistry, vol. 39, no. 3, pp. 665-668, 1996.

[4] P. W. Young, D. R. Buckle, B. C. C. Cantello et al., "Identification of high-affinity binding sites for the insulin sensitizer rosiglitazone (BRL-49653) in rodent and human adipocytes using a radioiodinated ligand for peroxisomal proliferator-activated receptor $\gamma$," Journal of Pharmacology and Experimental Therapeutics, vol. 284, no. 2, pp. 751-759, 1998.

[5] R. S. Satoskar, S. D. Bhanbarkar, and N. Nirmala, Pharmacology \& Pharmacotherapeutics, Popular Prakashan, India, 17th edition, 2001.

[6] J. Fuhlendorff, P. Rorsman, H. Kofod et al., "Stimulation of insulin release by repaglinide and glibenclamide involves both common and distinct processes," Diabetes, vol. 47, no. 3, pp. 345-351, 1998.

[7] A. H. Karara, B. E. Dunning, and J. F. McLeod, "The effect of food on the oral bioavailability and the pharmacodynamic actions of the insulinotropic agent nateglinide in healthy subjects," Journal of Clinical Pharmacology, vol. 39, no. 2, pp. 172-179, 1999.

[8] L. M. Keilson, S. Mather, Y. H. Walter, S. Subramanian, and J. F. McLeod, "Synergistic effects of nateglinide and meal administration on insulin secretion in patients with type 2 diabetes mellitus," Journal of Clinical Endocrinology and Metabolism, vol. 85, no. 3, pp. 1081-1086, 2000.

[9] P. Venkatesh, T. Harisudhan, H. Choudhury, R. Mullangi, and N. R. Srinivas, "Simultaneous estimation of six antidiabetic drugs — glibenclamide, gliclazide, glipizide, pioglitazone, repaglinide and rosiglitazone: development of a novel
HPLC method for use in the analysis of pharmaceutical formulations and its application to human plasma assay," Biomedical Chromatography, vol. 20, no. 10, pp. 1043-1048, 2006.

[10] J. Yao, Y. Q. Shi, Z. R. Li, and S. H. Jin, "Development of a RP-HPLC method for screening potentially counterfeit antidiabetic drugs," Journal of Chromatography B, vol. 853, no. 1-2, pp. 254-259, 2007.

[11] S. M. Aburuz, J. S. Millership, and J. C. McElnay, "The development and validation of liquid chromatography method for the simultaneous determination of metformin and glipizide, gliclazide, glibenclamide or glimperide in plasma," Journal of Chromatography B, vol. 817, no. 2, pp. 277-286, 2005.

[12] C.-C. Chou, M.-R. Lee, F.-C. Cheng, and D.-Y. Yang, "Solidphase extraction coupled with liquid chromatography-tandem mass spectrometry for determination of trace rosiglitazone in urine," Journal of Chromatography A, vol. 1097, no. 1-2, pp. 74-83, 2005.

[13] Z. J. Lin, W. Ji, D. Desai-Krieger, and L. Shum, "Simultaneous determination of pioglitazone and its two active metabolites in human plasma by LC-MS/MS," Journal of Pharmaceutical and Biomedical Analysis, vol. 33, no. 1, pp. 101-108, 2003.

[14] C.-G. Ding, Z. Zhou, Q.-H. Ge, X.-J. Zhi, and L.-L. Ma, "Simultaneous determination of metformin and glipizide in human plasma by liquid chromatography-tandem mass spectrometry," Biomedical Chromatography, vol. 21, no. 2, pp. 132-138, 2007.

[15] G. Ling, J. Sun, J. Tang, X. Xu, Y. Sun, and Z. He, "Liquid chromatography-electrospray ionization mass spectrometric method for determination of gliclazide in human plasma," Analytical Letters, vol. 39, no. 7, pp. 1381-1391, 2006.

[16] I. Niopas and A. C. Daftsios, "A validated high-performance liquid chromatographic method for the determination of glibenclamide in human plasma and its application to pharmacokinetic studies," Journal of Pharmaceutical and Biomedical Analysis, vol. 28, no. 3-4, pp. 653-657, 2002.

[17] C. Gedeon, B. Kapur, K. Aleksa, and G. Koren, "A simple and rapid HPLC method for the detection of glyburide in plasma original research communication (analytical)," Clinical Biochemistry, vol. 41, no. 3, pp. 167-173, 2008.

[18] D. Malli, E. Gikas, A. Vavagiannis et al., "Determination of nateglinide in human plasma by high-performance liquid chromatography with pre-column derivatization using a coumarin-type fluorescent reagent," Analytica Chimica Acta, vol. 599, no. 1, pp. 143-150, 2007.

[19] J. M. Sankalia, M. G. Sankalia, V. B. Sutariya, and R. C. Mashru, "Nateglinide quantification in rabbit plasma by HPLC: optimization and application to pharmacokinetic study," Journal of Pharmaceutical and Biomedical Analysis, vol. 44, no. 1, pp. 196-204, 2007.

[20] C. Yardımcı and N. Özaltın, "Simultaneous determination of rosiglitazone and metformin in pharmaceutical preparations by LC," Chromatographia, vol. 66, no. 7-8, pp. 589-593, 2007.

[21] C. Yardımcı, N. Özaltın, and A. Gürlek, "Simultaneous determination of rosiglitazone and metformin in plasma by gradient liquid chromatography with UV detection," Talanta, vol. 72, no. 4, pp. 1416-1422, 2007.

[22] B. L. Kolte, B. B. Raut, A. A. Deo, M. A. Bagool, and D. B. Shinde, "Simultaneous high-performance liquid chromatographic determination of pioglitazone and metformin in pharmaceutical-dosage form," Journal of Chromatographic Science, vol. 42, no. 1, pp. 27-31, 2004.

[23] C.-G. Ding, Z. Zhou, Q.-H. Ge, X.-J. Zhi, and L.-L. Ma, "Simultaneous determination of metformin and glipizide 
in human plasma by liquid chromatography-tandem mass spectrometry," Biomedical Chromatography, vol. 21, no. 2, pp. 132-138, 2007.

[24] H. N. Mistri, A. G. Jangid, and P. S. Shrivastav, "Liquid chromatography tandem mass spectrometry method for simultaneous determination of antidiabetic drugs metformin and glyburide in human plasma," Journal of Pharmaceutical and Biomedical Analysis, vol. 45, no. 1, pp. 97-106, 2007.

[25] K. Karthrik, G. S. Subramanian, C. M. Rao et al., "Simultaneous determination of pioglitazone and glimepiride in bulk drug and pharmaceutical dosage form by RP-HPLC method," Pakistan Journal of Pharmaceutical Sciences, vol. 21, no. 4, pp. 421-425, 2008.

[26] K. S. Lakshmi, T. Rajesh, and S. Sharma, "Determination of pioglitazone and glimepiride in pharmaceutical formulations and rat plasma by RP-LC," International Journal of PharmTech Research, vol. 1, no. 3, pp. 496-499, 2009.

[27] A. Gumieniczeka, H. Hopkala, and A. Bereckaa, "Reversedphase thin-layer chromatography of three new oral antidiabetics and densitometric determination of pioglitazone," Journal of Liquid Chromatography \& Related Technologies, vol. 27, no. 13, pp. 2057-2070, 2004.

[28] M. J. Sáiz-Abajo, J. M. González-Sáiz, and P. Consuelo, "Multiobjective optimisation strategy based on desirability functions used for chromatographic separation and quantification of Lproline and organic acids in vinegar," Analytica Chimica Acta, vol. 528, no. 1, pp. 63-76, 2005.

[29] Guidance for the Industry: Analytical Method Validation, US Food and Drug Administration, Center for Drug Evaluation and Research (CDER), Rockville, Md, USA, 2000. 

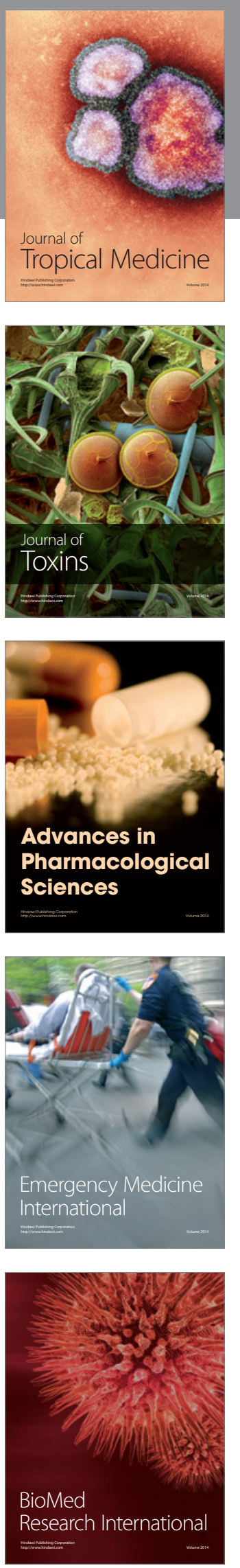
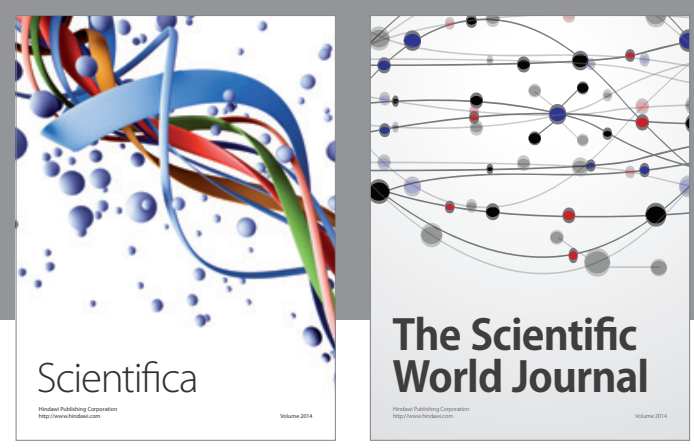

The Scientific World Journal
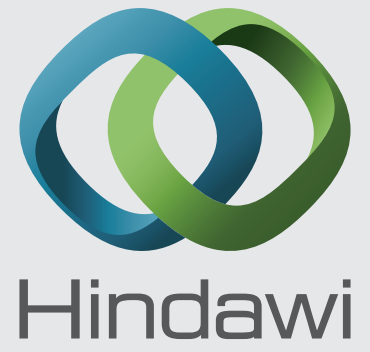

Submit your manuscripts at

http://www.hindawi.com
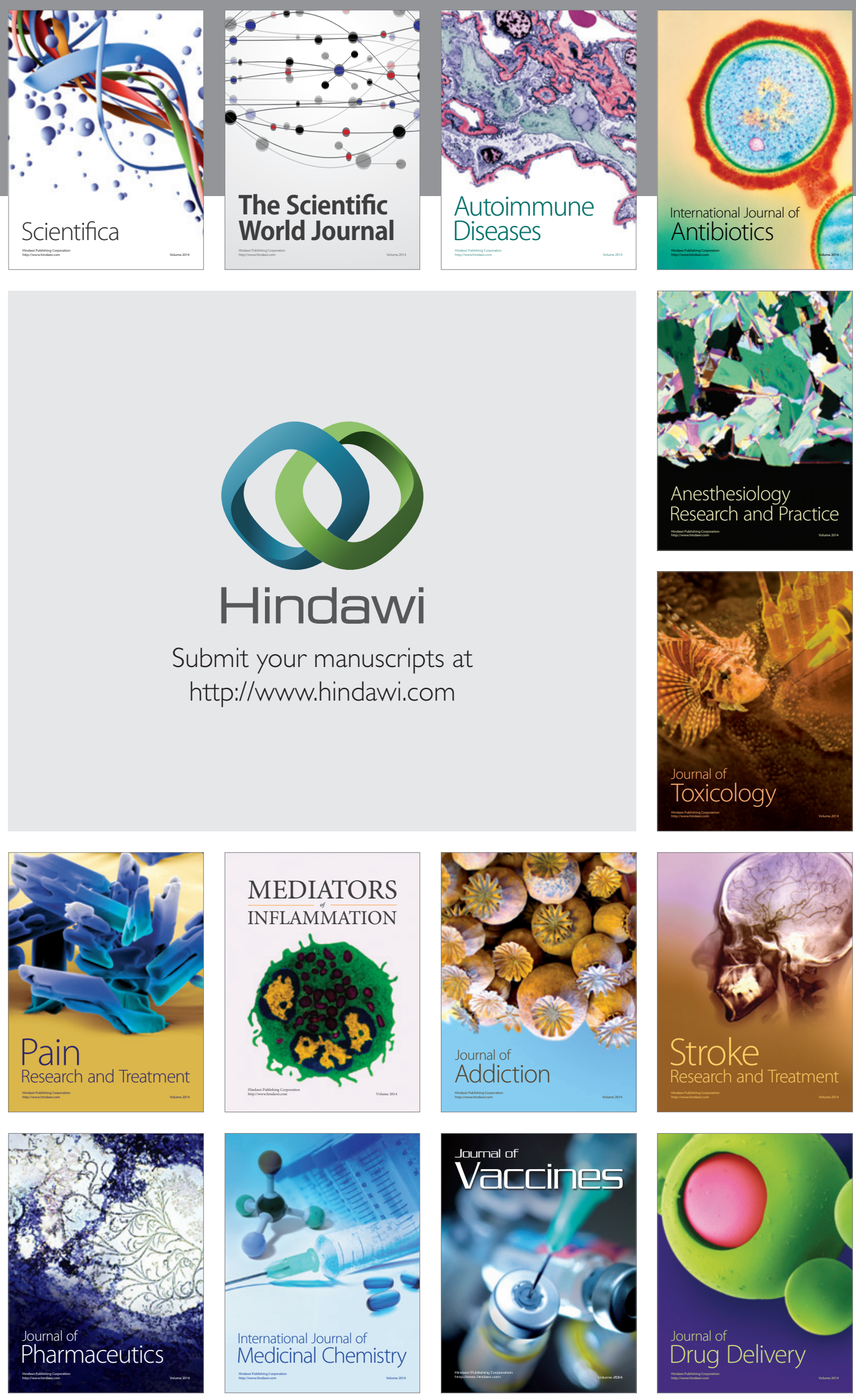